\title{
Um olhar para as articulações linguísticas na constituição de uma Semântica da Enunciação
}

\author{
Enunciation Semantics: a look at Linguistic relations \\ Luiz Francisco Dias \\ Universidade Federal de Minas Gerais/CNPq) ${ }^{1}$
}

\section{Introdução}

Este texto aborda a constituição de um campo de estudos na linguística brasileira. Tratase de um modelo de estudos da significação que tomou corpo no Brasil nos últimos 40 anos e sobre o qual atualmente se edificam inúmeros trabalhos de conclusão na graduação e na pósgraduação no nosso País, além de diversos livros, artigos, disciplinas, eventos, grupos de estudo, como também linhas e projetos de pesquisa. Efetivamente, trata-se de uma área que se consolidou no Brasil, e se encontra radicada em instituições de ensino e pesquisa de todo o País.

Especificamente, abordarei traços da fundação e desenvolvimento desse campo de estudos no trabalho do linguista Eduardo Guimarães.

A fundação desse campo se constituiu com fundamentos na teoria da argumentação de Oswald Ducrot, nas teses de Emile Benveniste sobre a subjetividade na linguagem, na filosofia da linguagem, especificamente na concepção de ato de fala, de John Austin, e em aspectos conceituais da Análise de Discurso ancorada no pensamento de Michel Pêcheux, na França, e de Eni Orlandi, no Brasil.

Certamente, o conjunto desses fundamentos não se recobrem ou se conformam entre si, nem teoricamente, nem metodologicamente. Isso exigiu um trabalho profundo de constituição de uma identidade de abordagem, marcada pela construção de uma consistência teórica com características inovadoras. Os contornos da elaboração desse modelo de análise justificam a denominação que Guimarães cunhou para o campo de estudos: Semântica da Enunciação.

Um dos pilares do arcabouço teórico-analítico está em um olhar para a língua do ponto de vista do modo como o sujeito se constitui por ela. Essa relação do sujeito com a língua é determinante para se criar um modelo de análise dos fatos linguísticos.

Vou iniciar esse olhar por um texto curto de Guimarães, datado de 1972. A seguir, busco elementos para compreender o modo de olhar a língua empreendido por Guimarães em um estudo clássico, voltado para as conjunções do Português, publicado em 1987. Após isso, vou buscar formulações de dois textos contemporâneos em relação ao estado atual do modelo teórico da Semântica da Enunciação, um de 2009 e outro de 2018. Por fim, farei um balanço pessoal do percurso traçado.

\section{Articulação linguística e a instância expressiva da linguagem}

Estamos no início da década de 1970. Vale observar que três modelos de análise linguística estavam em voga na época. Havia uma abordagem de viés estruturalista, já bastante consolidada, que primava pela descrição das categorias de estruturação sintagmática, tanto em línguas com escrita quanto em línguas sem escrita. Havia também outra abordagem, ainda jovem, mas em franca expansão, que olhava para as línguas com vistas a produzir uma hipótese forte sobre a sua geração na mente/cérebro, com a proposta de vislumbrar os princípios universais da linguagem humana. E ainda, um terceiro modelo, mais recente ainda para a época,

\footnotetext{
${ }^{1}$ Doutor em Linguística pela UNICAMP. Professor titular da Faculdade de Letras da UFMG. Pesquisador do CNPQ.
} 
que pregava a necessidade de se trilhar os caminhos da variabilidade das línguas, entendendo que parte dessas variações no mesmo sistema linguístico encontram-se determinadas por um quadro complexo de diversidades sociais, regionais e temporais.

O texto de 1972 foi escrito com vistas a discutir uma especificidade da classe dos advérbios em português. No entanto, não se percebe traços da determinação de nenhum desses modelos. Isso não significa que se trata de um texto superficial ou mesmo meramente impressionista em relação à especificidade adverbial destacada na publicação. Além disso, Guimarães afirma na introdução que um dos objetivos do texto é o de "poder contribuir para um aperfeiçoamento e simplicidade maior do ensino gramatical no curso médio". Dessa maneira, não se esperava mesmo que o texto pudesse trazer uma análise academicamente acabada do objeto de observação. No entanto, detecta-se nele um ponto de vista teórico que não tinha sido ainda formulado segundo uma direção mais ampla,tendo em vista um padrão metodológico mais apurado, mas que já aponta os caminhos para um olhar sobre a língua que difere daqueles que lastreiam os três modelos em voga na sua época.

Vou destacar os traços desse olhar sobre língua que já se vislumbravaindicador de uma abordagem enunciativa da ordem linguística.

O texto em foco apresenta como título "Variabilidade ou invariabilidade do advérbio em Português". Ele integra um pequeno conjunto de artigos do primeiro número da Série Estudos, uma publicação do Departamento de Letras da então Faculdade de Filosofia, Ciências e Letras Santo Tomás de Aquino, de Uberaba. Esse periódico adquiriu um espaço representativo entre os linguistas brasileiros nas décadas de 1970 e 1980.

O texto se inicia com o levamento das diferenças entre flexão e derivação, segundo Said Ali e Mattoso Câmara Jr.

No âmbito desse quadro de distinção, os afixos de flexão se constituem numa série fechada, exaustiva e necessária, como em "menino-menina-meninos-meninas", em que os sufixos flexionais de feminino [-a] e plural [-s] que aqui aparecem estão regularmente presentes nas principais classes nominais. Por sua vez, os afixos derivacionais não são afetados por essa regularidade.

Uma análise das ocorrências de marcação morfológica de grau indica que ele é também constituído sem a regularidade das séries fechadas, exaustivas e necessárias. É o que ocorre, por exemplo, com essa série: menino-menininho-meninote-meninozinho; menina-menininhameninazinha.

Com base em casos como esse, abrangentes na língua portuguesa, Guimarães acompanha Mattoso Câmara Jr na inserção do fenômeno do grau no quadro morfológico das derivações, e não no das flexões.

Nesse quadro em que as variações no âmbito dos pares opositivos singular/plural emasculino/feminino são regidos pela flexão e as variações relativas ao grau são regidas pela derivação, impõe-se um fato decisivo nessa diferenciação: o flexionamento recebe determinação sintática, motivando concordância no âmbito do grupo nominal (número e gênero) e entre esse grupo e o verbo(número e pessoa).

Na concepção de Câmara Jr. (1970), aponta Guimarães, a flexão é imposta pela própria natureza da frase. A seguinte afirmação de Guimarães (1972), a qual reforça essa perspectiva de Câmara Jr., é importante para compreendermos uma distinção importante quanto ao papel do falante na relação com língua: em situação de uso flexional, "o falante não poderia escolher se a efetuaria ou não. A própria língua traria em si a exigência da sua execução, do seu uso" (GUIMARÃES, 1972, p. 14).

Dessa maneira, se a flexão se situa no âmbito das relações sintáticas, ela se caracteriza por pertencer às relações fechadas, próprias da gramática. Por sua vez, a derivação, pelo fato de criar novos vocábulos, se caracteriza por pertencer às relações abertas, próprias do léxico. Guimarães corrobora mais uma vez a perspectiva de Câmara Jr. (1970: 82), por meio da 
seguinte afirmação: "para cada vocábulo, há sempre a possibilidade, ou a existência potencial, de uma derivação. A lista dos seus derivados não é exclusiva nem exaustiva".

Dado por assente que a flexão se situa nas relações gramaticais de uma língua e a derivação se situa no âmbito das relações lexicais, Guimarães se volta para o objeto específico do texto em foco: a natureza das variações do advérbio.

Nas ocorrências de "fala altíssimo" e de "fala baixinho", ambos os advérbios seriam derivados de alto e baixo, respectivamente.

Em específico, Guimarães aborda o problema do advérbio meio. Para isso, ele toma por base as seguintes ocorrências: "As palavras meias ditas, / Meias nos olhos escritas, / Voavam todas perdidas..." (GARRET, 1853, p. 14). Segundo ele, essa "flexão" em plural do advérbio meio não se constitui em algo regular na língua, e que inclusive pode ser omitida. Portanto, "não chega absolutamente a perturbar a nossa tese da invariabilidade do nome advérbio em Português" (GUIMARÃES, 1972, p. 17).

$\mathrm{Na}$ sua perspectiva, esse fato é "muito mais um recurso expressivo utilizado por escritores, de certa época, do que um processo gramatical." (GUIMARÃES, 1972, p. 18). Dessa maneira, ele formula a seguinte dedução para o problema do grau do advérbio, que aparece tanto nesse exemplo de Garret quanto em outras ocorrências: ele deve ser estudado juntamente com os nomes substantivos e adjetivos. No entanto, esse estudo não deve se realizar do ponto de vista gramatical, mas "de um outro ponto de vista: o expressivo" (GUIMARÃES, 1972, p. $18)$.

Assim, o texto de 1972 é concluído, mas o fechamento do texto deixa elementos para uma possível generalização de cunho enunciativo. Observe: ao corroborar a distinção de Câmara Jr acerca do caráter gramatical, portanto fechado, sistemático, da flexão, por um lado, e do caráter aberto, não sistemático, da derivação, por outro lado, Guimarães vislumbra uma instância em que o falante não opera diretamente na construção linguística: "o falante não poderia escolher se a efetuaria [flexão] ou não. A própria língua traria em si a exigência da sua execução, do seu uso" (GUIMARÃES, 1972, p. 14). Essa seria a instância do gramatical, uma instância da língua na qual o falante se inscreve na "exigência da sua [língua] execução". Por sua vez, na instância do expressivo, que também é da língua, o falante encontra um espaço para operar nas construções com relativa liberdade em relação às sistematicidades linguísticas. As construções com derivação de grau exemplificam a circulação do falante por esse espaço da ordem do expressivo.

Dessa maneira, os estudos linguísticos poderiam abrigar dois pontos de vista, isto é, dois "olhares" sobre a língua: um ponto de vista gramatical e um ponto de vista expressivo.

$\mathrm{Na}$ instância do gramatical, encontram-se as relações constituídas por concatenação e por recção (concordância e regência); na instância do expressivo, por outro lado, encontram-se as relações que atuam no léxico alterando os nomes, tendo em vista modos subjetivos de expressão.

A retomada desse texto de Guimarães poderia findar por aqui, destacando a sua contribuição na compreensão do fenômeno da gradualidade na língua. Porém, tenho elementos para ir além desse ponto. A reflexão que lá estava em germinação adquiriu um patamar de acabamento capaz de sustentar efetivamente um modelo de análise. Trata-se de um dos principais fios que tecem o trabalho acadêmico do pesquisador Guimarães: a relação entre língua, falante e enunciação. Naquele momento (1972), ele ainda não tinha condições de produzir consequências mais consistentes do que estava formulando com essa reflexão sobre o grau, embora essas consequências já estivessem levemente esboçadas nas suas palavras.

E que esboço é esse? O ponto de vista expressivo e o ponto de vista gramatical atravessam constitutivamente as categorias de substantivo, adjetivo e advérbio. Tendo em mente essa sutil generalização, pode-se estudar a língua por dois pontos de vista: aquele que se 
constitui pelo estruturante e aquele que se constitui pela enunciação. De um lado, somos afetados pelas sistematicidades linguísticas, de outro, pelas expressividades enunciativas.

Aquilo que ele esboçou não estava, evidentemente, nos textos de Said Ali e nem de Mattoso Câmara Jr. Ouso dizer que aqui se encontra rudimentos de um alicerce que viria a se tornar bastante firme, em cima do qual ele erigiu um modelo de semântica no Brasil de características próprias.Observa-se aqui o germe de uma linha de estudos que percorre a carreira do pesquisador, de 1972 até os dias de hoje.

Tudo indica que já se encontrava aqui, em estado latente, o vislumbrar de uma abordagem enunciativa da língua, exatamente na proposição de um ponto de vista expressivo nos estudos linguísticos. Com efeito, mais tarde, esses dois pontos de vista aparecem aprimorados na distinção entre articulações por dependência e articulações por incidência, como veremos adiante.

Evidentemente, no decorrer da década de 1970, o contato com os trabalhos de Ducrot, na França, e de Carlos Vogt, no Brasil, levaram as inquietações do texto de 1972 a tomarem contornos cada vez mais definidos, de maneira mais orgânica na dissertação de 1976, e em textos que começaram a ser publicados em periódicos ainda na década de 1970 e $1980^{2}$.

\section{Articulação linguística e orientação argumentativa}

Vou produzir um salto nessas etapas de desenvolvimento do modelo de abordagem da Semântica da Enunciação, porque me interessa discutir como a distinção que Guimarães esboçou em 1972 está inscrita em suas publicações intermediárias e recentes.

Nesse percurso virtual, passo pela obra Texto e Argumentação, de 1987, no sentido de observar como Guimarães formula a relação entre o sujeito, a enunciação e as articulações linguísticas. A obra se constitui em um estudo exaustivo das conjunções do Português, analisadas segundo uma abordagem enunciativa, com ancoragens nas teses de Ducrot sobre a argumentação,e no conceito de texto, da maneira como é concebido pela Análise do Discurso.

Após uma análise detalhada das conjunções, Guimarães (1987, p. 191-192) defende a tese segundo a qual a forma linguística é uma construção histórica:

Isto mostra como a forma linguística não pode ser prevista por combinações de traços aprioristicamente estabelecidos. Ao contrário, uma forma linguística é uma construção histórica e não lógica. Assim a determinação dos traços não é suficiente para explicar a forma de seu funcionamento. É a enunciação que explica. $\mathrm{E}$ isto na medida em que as formas guardam a sua exposição ao episódio enunciativo.

E é justamente com base na análise do funcionamento das conjunções, tendo em vista a enunciação, que ele formula uma conclusão sobre a diferença entre as articulações subordinativas e as articulações fundadas na coordenação e na segmentação.

A articulação entre orações realizadas pelas formas subordinativas estabelece hierarquia entre os termos relacionados, e dessa forma não produzem relação de orientação argumentativa, ou seja, "as orações subordinadas, tal como a definimos, não apresentam uma relação de classe argumentativa com a oração principal” (GUIMARÃES, 1987, p. 192).

Por outro lado, as construções constituídas pelas conjunções e, além disso, não só...mas (também), ou ... ou mantêm orientação argumentativa na articulação da primeira com a segunda orientação; as construções constituídas por mas, embora opõem orientações argumentativas; e

\footnotetext{
${ }^{2}$ A dissertação de Ana Cláudia Fernandes Ferreira, no âmbito da História das Ideias Linguísticas, desenvolve uma abordagem relevante desse trajeto do trabalho de Guimarães, a partir da dissertação dele, defendida em 1976.
} 
as construções logo, já que e pois articulam argumento e conclusão. Essas classes argumentativas se configuram como modos de se produzir orientações para a progressão textual.

Dessa maneira, as articulações do tipo subordinativas determinam a constituição da unidade oracional, ao passo que as articulações do tipo coordenativas e de segmentação participam da constituição textual, pela via das orientações argumentativas. Assim, no entender de Guimarães (1987, p. 195), existem formas na língua que adquirem especificidade no "funcionamento de regularidades gramaticais (construção da oração)" e formas que se especificam no "funcionamento de regularidades argumentativas (organização textual)".

Encontra-se aqui um ponto em que este estudo toca no estudo de 1972. Posso traçar um breve paralelo entre a distinção "instância do gramatical e instância do expressivo", esboçada naquele estudo e a distinção entre regularidade gramatical e regularidade argumentativa, formulada por Guimarães neste estudo de 1987. A primeira distinção explica a constituição da flexão em contraposição à derivação, especificamente a natureza da articulação entre uma base lexical e os sufixos flexionais, por um lado, e entre uma base e os sufixos derivacionais, por outro. A segunda distinção explica a constituição de uma unidade local no texto (a oração) como distinta das estruturações que se estendem para além das unidades locais, determinando direcionamentos textuais.

Se é possível traçar um paralelismo entre as duas distinções, é possível também observamos as diferenças que permeiam o quadro de fundo dessas distinções, em pelo menos dois aspectos.

No primeiro aspecto, aquilo que aparece vagamente como "expressivo" em 1972 adquire contornos teóricos bem definidos em 1987, com o conceito de orientação argumentativa. Ou seja, aquilo que se esboçava apenas como uma participação do sujeito falante na estruturação linguística, constituindo o conceito de expressivo, é abordado como uma orientação argumentativa, em que se toma um elemento A como aquilo que conduz o interlocutor a concluir C.

No segundo aspecto, não se vislumbra uma articulação linguística puramente contraída pela força estrutural, como se observa na explicação do fenômeno flexional, em contraposição a uma articulação provocada pela participação do sujeito, como no fenômeno derivacional. Com efeito, nos termos de Guimarães (1987, p. 12), "o sentido de uma sequência linguística inclui, sempre, a representação do sujeito da enunciação. Deste modo o nosso objeto de estudo se configura no interior de uma semântica da enunciação". Como isso adquire especificidade na configuração das articulações conjuntivas?

(...) se a subordinação é uma relação oracional, e a coordenação e segmentação são relações textuais, a orientação argumentativa é o modo de organização do texto cuja materialidade são a coordenação e segmentação. Coordenação, segmentação e subordinação, cada uma a seu modo, constituem aspectos do funcionamento discursivo. Por outro lado, tanto subordinação, coordenação como segmentação convivem com a polifonia da enunciação e a intertextualidade. Isto mostra como a dialogia interna percorre todo o texto, independente da representação de unidade textual ou oracional. (GUIMARÃES, 1987, p. 195)

Dessa maneira, as relações de subjetividade perpassam a constituição das relações linguísticas como um todo, seja nas representações de unidades locais, seja nas representações de ordem textual.

\section{Articulação linguística e acontecimento enunciativo}


Agora, parto para uma abordagem recente e atual no percurso de compreensão das relações de articulação linguística em Guimarães, especificamente, procuro observar essas relações em um texto de 2009 , tomando por base a seguinte passagem:

articulação é o procedimento pelo qual se estabelecem relações semânticas em virtude do modo como os elementos linguísticos, pelo agenciamento enunciativo, significam sua contiguidade. Ou seja, a organização das contiguidades linguísticas se dá como uma relação local entre elementos linguísticos, mas também e fundamentalmente por uma relação do Locutor (enquanto falante de um espaço de enunciação) com aquilo que ele fala. Uma articulação é uma relação de contiguidade significada pela enunciação. (GUIMARÃES, 2009, p. 51)

Essa perspectiva, a qual concebe as articulações linguísticas como relações significadas pela enunciação, apresenta um relevante grau de originalidade.

Não é difícil perceber que a perspectiva da participação do falante nas construções linguísticas (esboçadas no texto de 1972 pela noção de expressividade) e a perspectiva da construção histórica das formas linguísticas, de 1987, adquirem densidade e mais especificidade, como podemos observar na formulação de 2009 , tendo em vista a entrada efetiva do conceito de acontecimento enunciativo no arcabouço teórico que ampara a subjetividade na linguagem.

Efetivamente, hoje o foco do trabalho não são as construções linguísticas e as possibilidades de participação do sujeito nessas construções, mas o acontecimento da enunciação, em que o locutor é agenciado como falante num espaço de enunciação.

Há que se observar a distinção entre três tipos de articulação, no sentido de se produzir mais consequências desse salto de perspectiva, na busca de uma concepção mais consistente de subjetividade na linguagem.

A enunciação, e especificamente a relação que o locutor estabelece com o seu dizer,dadas as determinações históricas do seu agenciamento como sujeito nos espaços sociais, é um fator determinante na configuração dos elementos articulados em uma sequência linguística.

Na sequência os meninos de vermelho, segundo Guimarães, os elementos linguísticos contíguos "os" e "de vermelho" vinculam-se a "meninos" constituindo, em articulação, um grupo nominal. Nesse tipo de articulação, "o acontecimento especifica uma operação pela qual o Locutor relaciona elementos do enunciado." (GUIMARÃES, 2009: 51). Trata-se da articulação de dependência.

Por sua vez, em os meninos e as meninas, os dois nomes encontram-se organizados pela articulação em um processo de acúmulo ou adição numa relação de contiguidade, frente ao fato de que os dois elementos articulados são da mesma natureza categorial. Tem-se nesse caso uma articulação de coordenação.

Por fim, em "Até Pedro veio", a articulação que "até" estabelece com Pedro veio é de outro tipo, pois não criaria uma relação de dependência, nem de coordenação, mas de incidência. Nesse caso, segundo ele, "o acontecimento relaciona uma operação pela qual o Locutor relaciona sua enunciação com o enunciado.” (GUIMARÃES, 2009: 51).

O papel do até na ocorrência apresentada não é o mesmo constatado em "Pedro foi até o muro e voltou" ou "Carla ficará na casa da tia até fevereiro". Nesse caso, tem-se verdadeiramente uma preposição, a qual expressa limites espacial e temporal, respectivamente. Já na ocorrência "Até Pedro veio", o vocábulo até é comumente classificado pela gramática como advérbio. No entanto, o funcionamento enunciativo indica que o seu papel semântico vai muito além de um determinador circunstancial. 
Em resumo, a articulação de dependênciae a articulação de coordenaçãoocorrem entre elementos que se vinculam no âmbito do enunciado, contraídas pelo agenciamento dos locutores no acontecimento enunciativo, ao passo que a articulação de incidência se dá pela relação entre enunciação e enunciado, e também agenciada pelo Locutor.

Há que se observar, portanto, que as articulações locais no âmbito do enunciado, realizadas gramaticalmente, não aparecem como relações impostas pelo sistema linguístico, do ponto de vista formal. Com efeito, as relações entre formas linguísticas são contraídas em função da constituição de sentido no acontecimento enunciativo, tendo em vista o agenciamento do locutor nos espaços de discursividade que permeiam o acontecimento enunciativo.

Por outro lado, nas articulações não locais, que não se configuram tão somente pelas relações sintagmáticas, elementos da própria enunciação incidem sobre a estruturação do enunciado, marcando diretamente a presença do sujeito pelas formas linguísticas.

No seu livro mais recente, Semântica: enunciação e sentido, Guimarães (2018) formula o seguinte:

Considero que o acontecimento da enunciação se produz pelo funcionamento da língua nos espaços de enunciação, conceito decisivo, do meu ponto de vista, para colocar a questão da língua e da enunciação em outros termos, na história dos estudos enunciativos. Nestes espaços de enunciação, os falantes das línguas que os constituem politicamente são agenciados, também politicamente, a dizer segundo uma divisão de lugares de enunciação nas cenas enunciativas.

Aqui estaria, de uma maneira teoricamente consistente, a questão da língua, do falante e da enunciação, observando-se a relação entre as sistematicidades linguísticas (o funcionamento da língua nos espaços de enunciação) e as expressividades enunciativas (os falantes constituídos em agenciamento político com o dizer nas cenas enunciativas).

O estudo das relações de articulação (dependência, coordenação e incidência), juntamente com as relações por reescrituração, demonstrando ao mesmo tempo a consistência interna e a independência relativa do enunciado, aprofunda e especifica teoricamente o quadro esboçado 46 anos antes, concebido na relação entre as sistematicidades e as expressividades.

\section{Considerações finais}

Eu começo a encerrar este texto, a título de homenagem ao pesquisador e meu orientador Guimarães, com o excerto de uma publicação de 2009, já comentada no presente texto. Tratase de uma síntese que tomo como basilar para se compreender a relação de filiação do meu trabalho de pesquisa com a Semântica da Enunciação, relação essa exposta no livro que publiquei recentemente: Enunciação e relações linguísticas. Na minha visão, esse excerto constitui-se numa formulação decisivapara a compreensão da passagem do esboço de concepção de 1972 para uma malha conceitual estável em 2018: "São as relações de linguagem que constituem sentido. E mais especificamente, são as relações enunciativas do acontecimento que constituem sentido. O sentido não se reduz a uma mera relação interna em uma estrutura entre os elementos da estrutura, independentemente de qualquer exterioridade" (GUIMARÃES, 2009, p. 50).

Alinhado com essa perspectiva de constituição de uma semântica, afirmei no meu trabalho que ela se distingue das "abordagens que concebem o semântico em termos de propriedades da exterioridade linguística, ou em termos da funcionalidade da linguagem na interação imediata. Ao invés de perguntar pela natureza das coisas na relação com o homem, ou pela economia linguística na interação entre os homens, perguntamos pela natureza do dizer humano na constituição [socio-histórica] da ordem das coisas.” (DIAS, 2018, p. 254) 
Por fim, frente a esse traçado que apresenta a minha percepção do nascimento e desenvolvimento da semântica da enunciação,tendo em vista as relações entre língua, enunciação e sujeito, gostaria de ancorar esse percurso em uma avaliação pessoal.

Na minha perspectiva, trata-se de um trabalho que se desenvolveu sob a influência de Ducrot, embora com expressiva independência em relação às suas teses; que também se inspirou em Benveniste, arrebatado pela visão da constituividade da língua na condição humana; e que tomou corpo sob o impulso de Pêcheux e Orlandi, convicto de que o acontecimento da enunciação tem origem onde se constituem as formações histórico-sociais, dispersas nas discursividades da clivagem política que define o falante nos espaços de enunciação.

Nesse espaço de 46 anos de trabalho, muito parcialmente pontuados no presente texto, entre o primeiro esboço de uma abordagem linguística que aponta para a interposição dos modos subjetivos de expressão nas estruturações gramaticais ao aprimoramento dos conceitos de articulação e reescrituração constitutivos de uma visão inovadora do acontecimento enunciativo, Guimarães elabora um modelo de estudo científico da significação com fortes traços de autoria brasileira.

\section{Referências bibliográficas}

CÂMARA JR., J. M. Estrutura da língua portuguesa. Petrópolis: Vozes, 1970.

DIAS, L. F. Enunciação e relações linguísticas. Campinas: Pontes, 2018.

FERREIRA, A. C. F. Um nome de teoria estabilizado, sentidos em movimento: a semântica argumentativa na história. Campinas, Programa de Pós-Graduação em Linguística UNICAMP. Dissertação de mestrado, 2005.

GARRET, A. [1853]. Folhas caídas. Porto: Porto Editora, s/d.

GUIMARÃES, E. Variabilidade ou invariabilidade do advérbio em Português. Série Estudos, Uberaba, n. 1, 1972, p. 13-18. 1987.

. Texto e argumentação: um estudo de conjunções do Português. Campinas: Pontes,

- A enumeração: funcionamento enunciativo e sentido. Cadernos de Estudos Linguísticos, Campinas, v. 51, n.1, 2009, p. 49-68.

. Semântica: enunciação e sentido. Campinas: Pontes, 2018.

Recebido em: maio de 2019.

Aprovado em: dezembro de 2019.

Como citar este trabalho:

DIAS, L. F. Um olhar para as articulações linguísticas na constituição de uma

Semântica da Enunciação. Traços de Linguagem. V.3, n.2, p. 8-15, 2019. 